\title{
Stock assessment of sharks in the northern part (Iranian waters) of the Persian Gulf
}

\author{
Nassir Niamaimandi ${ }^{1, ~}$, Toraj Valinassab ${ }^{2}$, Gholam-Abbas Zarshenas ${ }^{2}$ \\ ${ }^{1}$ Iran Shrimp Research Institute, P.O.Box: 1374, Bushehr-Iran \\ ${ }^{2}$ Iranian Fisheries Research Organization, Tehran-Iran
}

\section{Email address:}

nmaimandi@yahoo.com (N. Niamaimandi)

\section{To cite this article:}

Nassir Niamaimandi, Toraj Valinassab, Gholam-Abbas Zarshenas. Stock Assessment of Sharks in the Northern Part (Iranian Waters) of the Persian Gulf. Agriculture, Forestry and Fisheries. Vol. 3, No. 5, 2014, pp. 397-400. doi: 10.11648/j.aff.20140305.21

\begin{abstract}
This study was analyzed the annual catch and trawl survey data of sharks in the northern part of the Persian Gulf $\left(26^{\circ} 30^{\prime}\right.$ to $30^{\circ} 00^{\prime} \mathrm{N}$ and $49^{\circ} 00^{\prime}$ to $\left.56^{\circ} 00^{\prime} \mathrm{E}\right)$ from 2004 to 2009 . Trawl survey was conducted by research vessel Ferdous, equipped with bottom trawl nets in meshes $400 \mathrm{~mm}$ and $80 \mathrm{~mm}$ at body and cod-end respectively. Ten stratums were selected in the study area and 199 stations were randomly trawled. The density (CPUA) of shark resources was estimated based on swept area method. Annual total catch was obtained from Iranian fisheries organization (Shilat). The results of catch per unit area showed $250.7 \mathrm{~kg} / \mathrm{nm}^{2}$ in 2004 to $49.7 \mathrm{~kg} / \mathrm{nm}^{2}$ in 2009. There was a high degree of variability of CPUA among different areas and the maximum was estimated $1870.8 \mathrm{~kg} / \mathrm{nm}^{2}$ in Nayband and Mogham. In catch composition data, sharks have a decreasing trend from $4.2 \%$ in 2004 to $2.9 \%$ in 2009 that shows a decline with an annual average 1.3\% during 2004-2009.This results suggesting that the shark resources are overexploited and the current effort is far higher than the effort required harvesting optimum yields.
\end{abstract}

Keywords: Shark Resources, Iranian Waters, Persian Gulf

\section{Introduction}

Sharks and their relatives (the skates, rays and chimaeras) are highly divers group abouh 1000 species that evolved over 400 million years ago (McAuley et al., 2002). This fishes (class Chondrichthyes) are chracterised by a cartilaginous skeleton, multiple gill oppening, skin covered with modified teeth instead of scale and external male reproductive organ.

Sharks have biological characteristics such as: low growth rate, late age of maturity, long life span and low fecundity which make them vulnerable to heavy fishing pressure and recovery times from overfishing are prolonged (Simpfendorfer et al., 2005; Abella, 2010).

Over 26 species of sharks are known to inhabit in the Persian Gulf. Carcharhinidae is the most species-rich family (16 species) present. The first substantiated Gulf records of the spinner shark Carcharhinusbrevipinna, blacktip reef shark C. melanopterus, and scalloped hammerhead Sphyrnalewini are provided, along with a new record of the rarely reported grey nurse shark Carcharias taurus (moore et al., 2012). Sharks play an essential roll in maintaining the health of the environment.

Although there is uncertainly evidence about the status of these species but total catch has significantly declined and it can be resulted of the lack of shark fishing regulation and fishing limits. It has been concern the deteriorating status of the sharks in the region.In the studied area, sharks are caught by long line, gillnets and trawl. Sharks not only are target species but also they are as a part of the by-catch that it makes an increase in discard and an undesired mortality. In the studied area caught sharks are either landed or discarded. The reduction in biomass of sharks is more evident in the case of demersal species, but also occurred in the case of pelagic ones. To ensure long-term, sustainable fisheries, prevent population collapse and maintain ecosystem function, precautionary management of these species is required (Simpfendorfer., et al., 2008).

Knowledge of shark resources in the Persian Gulf area is important in fishery management in determining whether an area is heavily fished or under-exploited to allow possible management measure to be taken. The objective of this paper is to provide the current status of the shark resources 
including total exploitation, catch per unit area data and comparing of total catch with shark exploitation rates. The authors intend to provide critical information to create an action plans that enhance the fisheries management of sharks in the Persian Gulf.

\section{Method and Material}

The data for analyzing were included of annual catch rate of sharks that was obtained from Iranian fisheries organization (shilat) and as well as data from regional fishery survey (bottom trawl sampling) from 2004 to 2009. Investigated area was located between $26^{\circ} 30^{\prime}$ to $30^{\circ} 00^{\prime}$ Nand $49^{\circ} 00^{\prime}$ to $56^{\circ} 00^{\prime}$ Ecovering about $1000 \mathrm{~km}$ long and $6600 \mathrm{~nm}^{2}$ and extends from Khuzestan through Bushehr in the northern middle part to Hormozgan waters in the strait of Hormuz (Fig. 1). In trawl survey 9stratums A to I (Fig 1) within 10-50m depth was used for towing and approximately 199 stations were randomly selected.

Sampling was carried out by R/V Ferdous with 45.4 long, $10 \mathrm{~m}$ width stretchedand $1600 \mathrm{HP}$ engine.The standard bottom trawl net with $400 \mathrm{~mm}$ mesh size at body and $80 \mathrm{~mm}$ at cod-end with head-rope length $72 \mathrm{~m}$ was used. Towing was operated at 3-4 knots for one hour.

Catch per unit area (CPUA) was calculated by swept area method (Sparre and Venema, 1992). Swept area or effective path swept (a) was estimated from:

$$
\begin{gathered}
A=D * h * X_{2} \\
D=V * t
\end{gathered}
$$

Where $\mathrm{V}$ is the velocity of the trawl over the ground when trawling, $h$ is the length of the head-rope, $t$ is the time spent trawling, $\mathrm{X}_{2}$ is that fraction of the head-rope length that was assumed 0.65 in the present study.

Catch Per Unit Area (CPUA) was estimated by dividing the catch by the swept area (in square nautical miles) as defined by following formula (Sparre and Venema, 1992).

\section{$\mathrm{CPUA}=\mathrm{C} / \mathrm{a}$}

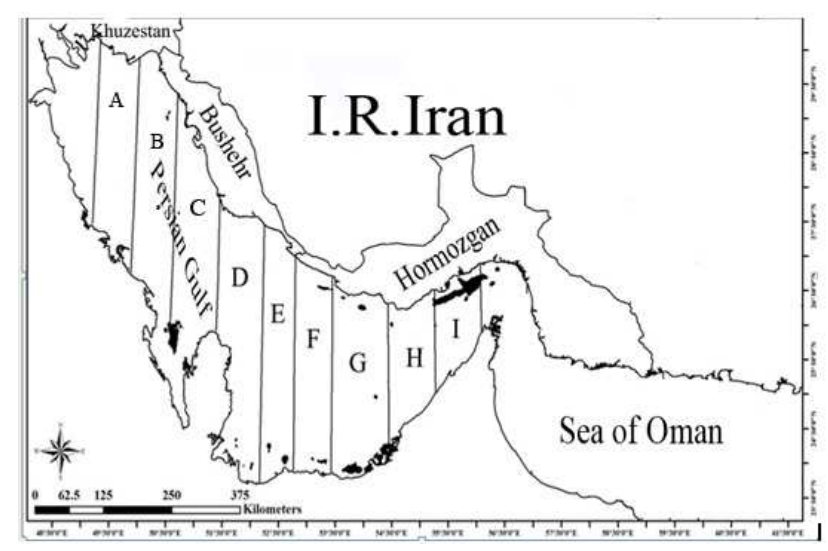

Fig 1. Map of the sampling area in Iranian southern provinces waters in the Persian Gulf.
Where CPUA is the mean of the catch in every station and a is towed area in every station. Total of CPUA in every stratum is $\mathrm{CPUA}=\mathrm{Ct} / \mathrm{A}$ that is total catch of every stratum (Ct) in whole sampling area (A).

\section{Results}

In trawl survey about 113 species or species group were identified. Sharks were divided in two groups included of Whitecheek shark(Carcharhinusdussumieri)and other shark species that called sharks. In catch composition data, sharks are not grouped by species and just mentioned as one group.So in the present study data analysis is done on the sharks as a one group of marine organisms.

Catch per unit area was estimated in maximum 250.7 $\mathrm{kg} / \mathrm{nm}^{2}$ in 2004 to minimum $33 \mathrm{~kg} / \mathrm{nm}^{2}$ in 2008 (Fig. 2). This estimation has basically shown a strong negative trend from 2004 to 2009 . This declining in every year is approximately included of half of the density comparing previous year.

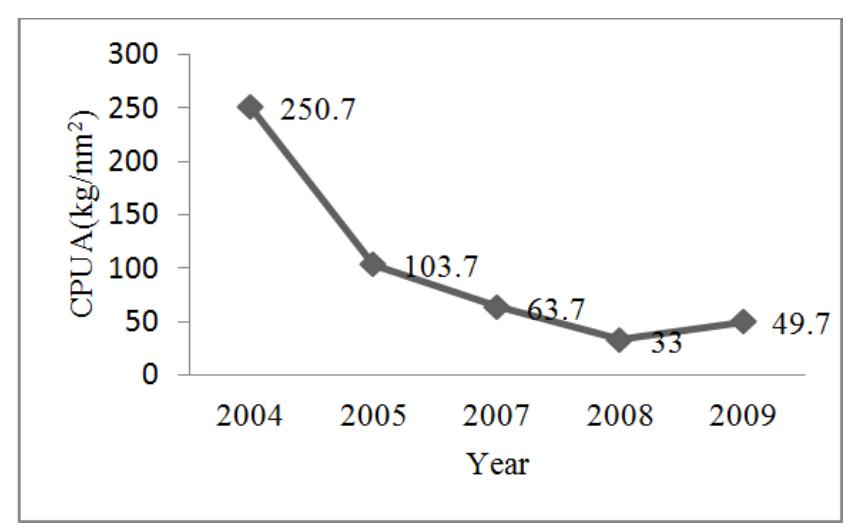

Fig 2. CPUA ( $\mathrm{kg} / \mathrm{nm} 2)$ of sharks in the Iranian waters, Persian Gulf (20042009).

Mean density (CPUA) being proportional to the Total annual catch rates, tend to follow the same distribution pattern.Both results showed a decreasing trend from 2004 to 2009 (Fig 3). Maximum catch was obtained in 2005 about $14000 \mathrm{t}$ and minimum in 2009 around 10000. Maximum and minimum of CPUA was estimated $250.7 \mathrm{~kg} / \mathrm{nm}^{2}$ in 2004 and $33 \mathrm{~kg} / \mathrm{nm}^{2}$ in 2008 respectively.

Figure 4 shows the percentage of the sharks in the total landing. In the annual catch composition, sharks were between $4.2 \%$ (2004) to $2.9 \%$ (2009) of the total in whole area. This result shows a decline trend of $1.3 \%$ during study period.

Catch per unit effort exhibited a decreasing trend from 2004 to 2009 (Fig. 5). The highest CPUA was observed at $30-50 \mathrm{~m}$ depth in 2004 and minimum was estimated in 20072008 in waters less than $10 \mathrm{~m}$ deep.

The results of CPUA in different stratum exhibited in figure 6. Maximum of catch per unit area $\left(1870 \mathrm{~kg} / \mathrm{nm}^{2}\right)$ was observed at stratum $\mathrm{F}\left(53^{\circ} 36^{\mathrm{E}} \mathrm{E}\right.$ and $\left.52^{\circ} 45^{\mathrm{E}} \mathrm{E}\right)$ that is located between Nayband and Mogham areas. This area was about $317 \mathrm{~nm}^{2}$. 


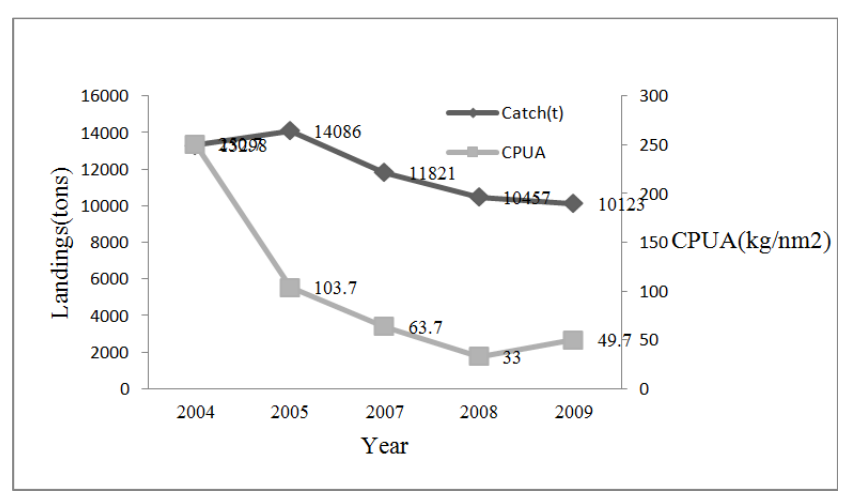

Fig 3. Total catch and Catch Per Unit Area (CPUA) of sharksin the Iranian waters of Persian Gulf (2004-2009).

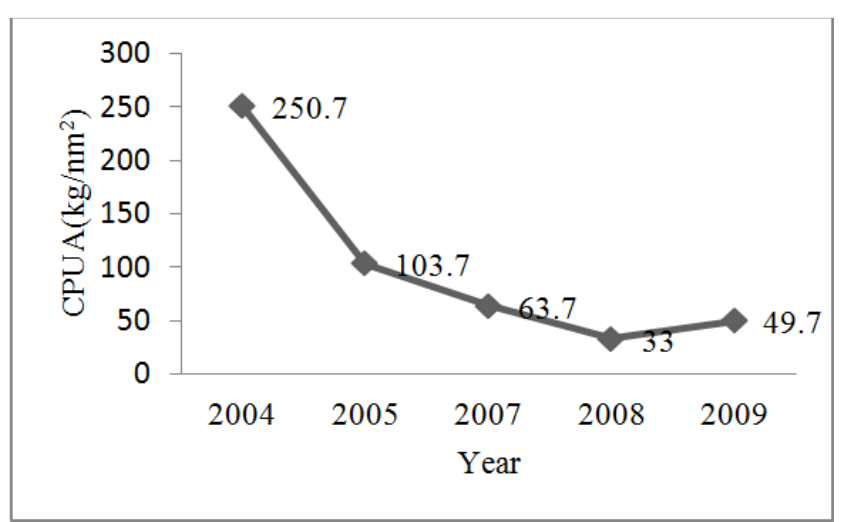

Fig 4. Percentage of the sharks in the total catch in the Iranian waters of Persian Gulf (2004-2009).

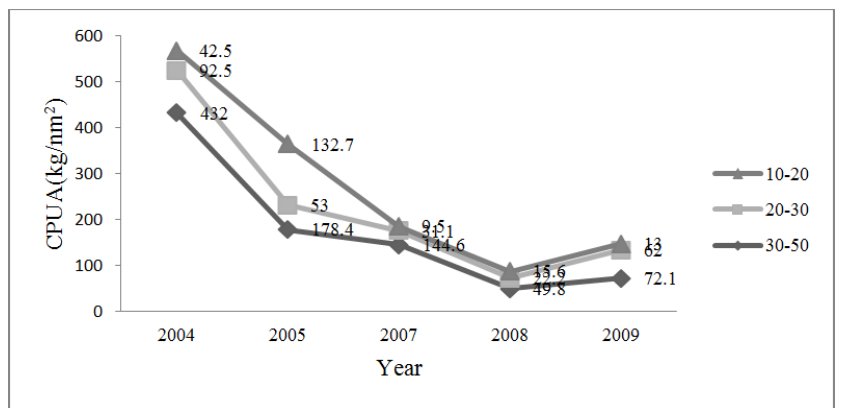

Fig 5. Catch Per Unit Area (CPUA) of sharks in different depths in the Iranian waters of Persian Gulf (2004-2009).

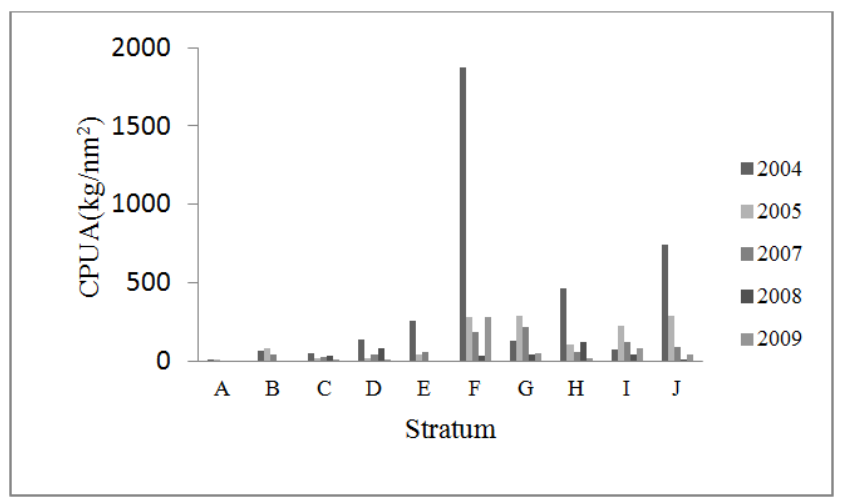

Fig 6. Catch Per Unit Area (CPUA) of sharks in different stratum in the Iranian waters of Persian Gulf (2004-2009).

\section{Discussion}

In the present study the results showed that annual catch and CPUA of the sharks have a decreasing trend from 2004 to 2009 . Sharks have comprised between $4.2 \%$ and $2.9 \%$ of total landings.

In the studied area caught sharks are either landed or discarded. Some of the sharks catch for fins and the finless animal back into the water and some of them are as by-catch. Both finned and by-catch suffers $100 \%$ mortality and not mentioned in the reported catch.Shark fin has become a major trade within some Gulf's countries markets. Due to the fin trade of some shark species, the resources of them are more under catch pressure and it made them more vulnerable. Comparing to the other fish stocks, sharks also have low productivity and pressure on the resources make more difficulties to rebuild depleted stocks.

The estimate of average rate of illegal, unregulated and unreported (IUU) of world shark catch is about 63 million sharks per year for year 2000 (Worm et al., 2013). This estimate changes only slightly from 2000 to 2010 (61 million). This number is also similar to estimate of shark mortality from the fin trade of 73 million individuals (Clarke et al., 2006).

The production level, in relation of total catch and CPUA estimation, indicated that, there is high pressure and intensive of fishing activity on shark's exploitation. Sharks are not usually caugth to use for body meat and due to high value of fin in some countries of the Persian Gulf, the animals fin removed and body being discarded at sea. Such discards are not usually reported and make a bias in statistic of catch. To avoid further depletion and possible distinction of sharks, some urgent decisions are nessecery. Catch limit, critical protection habitats, and Anti-finning regulation can help to conservation of shark resources in the Persian Gulf area. A plan for data collection, monitoring and education of fishermen can also enhance the conservation and fisheries management of sharks in this area.

The data available in the present study are not sufficient to identify the limit of maximum sustainable yield of shark species. This possibility is also existed that, the stocks in the northern part of the Persian Gulf being in common with the adjacent waters in the southern parts (Arabian countries). In such case, the degree of exploitation by neighboring countries will influence on data analysis. These regulations should be introdused by collaboration of all countries in the region. Until such time, the information presented in this study can provide guidance to planingfishery development and management of the shark resources and also serve as a source of information.

\section{Acknowledgments}

This research has been funded by Iranian Fisheries Research Organization (IFRO). The authors gratefully acknowledge use of the Iranian Fisheries Organization (Shilat) statistic of catch. Special thanks to those that 
participated in trawl survey particularly Momeni, Mobarezi, Safikhani, Dehghani, Kamali, Ansari, Kashi, Khorshidian, Shabani, Moradi and Esmaeili.

\section{References}

[1] Abella, A. 2010. Stock assessment models and their application to skates. In: Serena F., Mancusi C., Barone M. (eds). Field identification guide to the skates (Rajidae) of the Mediterranean Sea. Guidelines for data collection and analysis Biol. Mar. Mediterr., 17 (Suppl. 2): 204 p.

[2] Clarke, S.C., McAllister, M.K., Milner-Gulland, E.J., Kirkwood, G.P., Michielsens, C.G.J., Agnew, D.J., Pikitch, E.K., Nakano, H., Shivji, M.S., 2006. Global estimates of shark catches using trade records from commercial markets.Ecological letter, Vol. 9. 1115-1126.

[3] McAuley, R., Newbound, D., Ashworth, R., 2002. Field identification guide to western Australian sharks and sharklike rays. Department of fisheries, Pert, Western Australia. Fisheries occasional publication, No. 1
[4] Moore,, A.B.M., Ward, R.D and Peirce, R. 2012. Sharks of the Persian Gulf: a first annotated checklist (Chondrichthyes: Elasmobranchii). Zootaxa 3167: 1-16.

[5] Simpfendorfer, C.A., Freitas, G.F., Wiley, T.R., Heupel, M.R. 2005. Distribution and habitat partitioning of immature bull sharks (Carcharhinusleucas) in a Southwest Florida Estuary. Estuaries 28:78-85

[6] Simpfendorfer, C.A., Cortés, E., Heupel, M., Brooks, E., Babcock, E., Baum, J., McAuley, R., Dudley, S., Stevens, J.D., Fordham, S. and Soldo, A. 2008. An integrated approach to determining the risk of overexploitation for data-poor pelagic Atlantic sharks. ICCAT SCRS/2008/140.

[7] Sparre, P., Venema, S.C. 1992. Introduction to tropical fish stock assessment, part 1-manual. FAO fisheries technical paper 306/1. 311-314.

[8] Worm, B., Davis, B., Kettemer, L., Ward-Paige, C.A., Chapman, D., Heithaus, M.R., StevenT.Kessel, S.T., SamuelH.Gruber, S.H. 2013. Global catches, exploitation rates, and rebuilding options for sharks. Marine policy 40. 194-204. 